\section{The clock is ticking}

The clock is ticking and BDIA Dental Showcase is just around the corner. There's still time to register to join thousands of dental professionals on 17-19 October at Birmingham NEC for three days of innovation, insight and inspiration. This year's event has some exciting new features as well as the welcome return of some of the more popular elements from previous years. Without doubt there is something to suit everyone's tastes and interests so, if you haven't already done so, register and save your place now.

BDIA Dental Showcase is the biggest trade exhibition in the UK, so for many people the draw of this event is the unrivalled plethora of dental suppliers, manufacturers and associations all conveniently placed under one roof.

All major dental associations will be in attendance, and this year, they will all be conveniently congregated in the new Associations Hub. Also new for 2019 is the bespoke Specialist Zone, where visitors who have specialised, or are looking to specialise, can boost their knowledge within small, relaxed sessions. For example, there'll be representatives talking about orthodontics and implants to name just two of the many areas that will be represented.

BDIA Dental Showcase is also the ideal time to mix business with pleasure. Discover the new-for-2019 Networking Bar where you can meet with current or former colleagues and other peers during

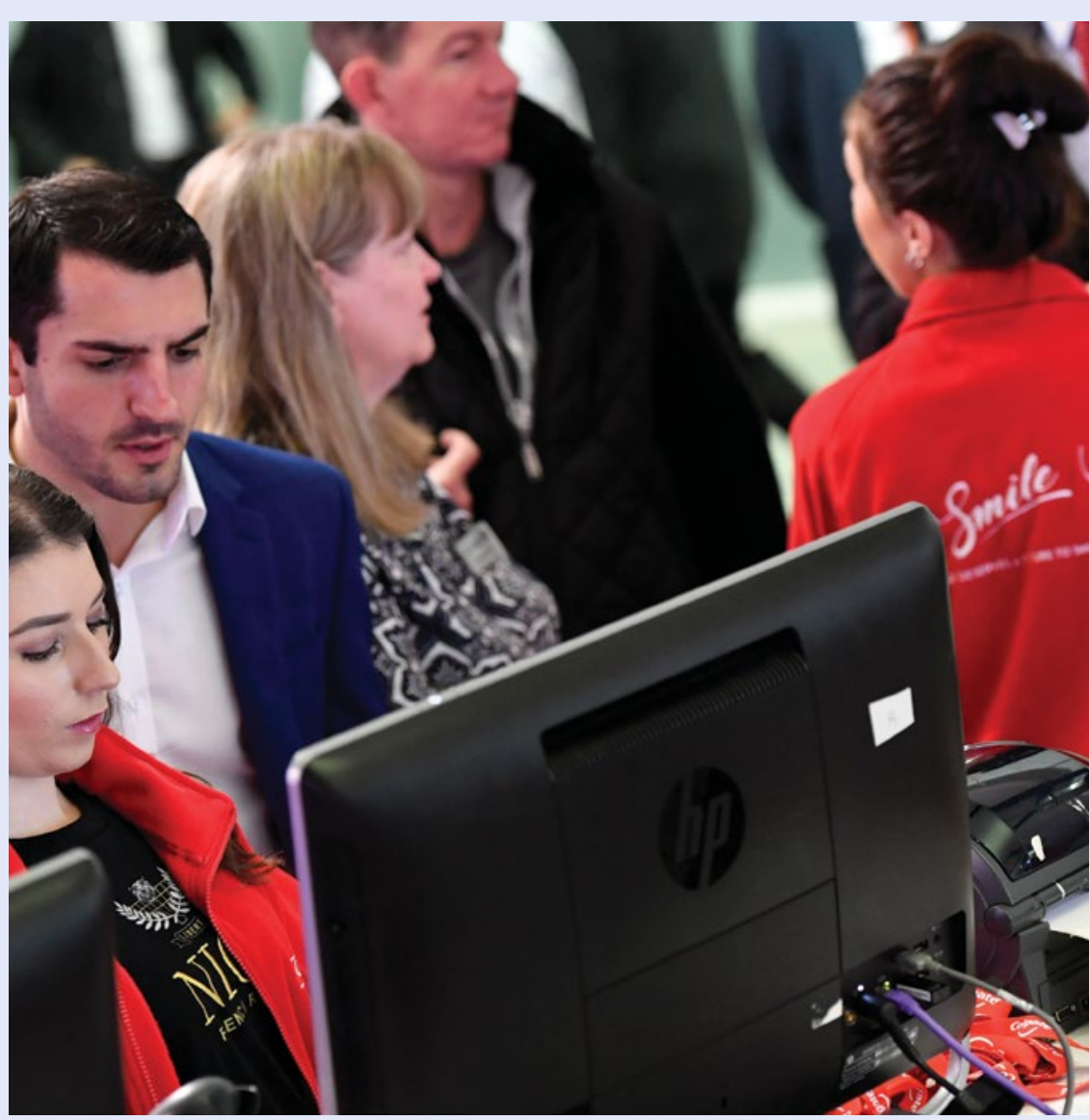

informal drinks receptions. This year, there will also be a Practice Owners' Lounge, allowing practice owners to recharge between lectures and appointments and access free refreshments.

BDIA Dental Showcase wouldn't be the same without a social event to round off the week, and this year is no different.
Choose between the Bridge2Aid Bash and the FD Ball, each a perfect way to relax and catch up with both old and new acquaintances.

To register free for BDIA Dental Showcase and benefit from all these unmissable features, visit dentalshowcase. com/register.

\title{
The eco-friendly autoclave
}

Are you looking to cut down the energy usage in your practice? Make an ecofriendly choice with the help of Eschmann.

The Little Sister SES 2020N autoclave from Eschmann features a number of innovative features. From rapid drying cycles to enhanced compliance, every single aspect of the system has been designed to ensure that it streamlines your day-to-day workflows.

Furthermore, as it has a larger 17-litre capacity that can hold five full size instrument trays you don't need to run it regularly, quickly helping to cut down the amount of water and electricity used.

For more information on the highly effective and affordable range of

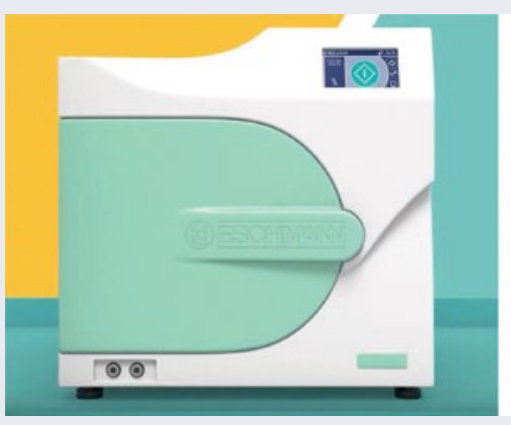

decontamination equipment and products from Eschmann, visit www.eschmann. co.uk or call 01903753322 . 